\title{
Computational Optimizations in wildland fires for Bulgarian test cases
}

\author{
Nina Dobrinkova \\ Institute of Information and \\ Communication Technologies - \\ Bulgarian Academy of \\ Sciences, acad. Georgi Bonchev \\ bl. 2, Bulgaria, Email: \\ ninabox2002@gmail.com
}

\begin{abstract}
In this article we are going to present the optimizations that has been done through different types of modeling actions on wildland fires for Bulgarian test cases. We will present approaches where meteorological data along with terrain specific relief and vegetation coverage are modeled in a way to present credible scenarios for wildland propagation used for calibration purposes of the different approaches. This work aims to prove that the used modeling tools can be used also in real time decision support for the responsible authorities when it comes to wildland fire propagation and the measures corresponding to limitation of its devastating consequences for the nature and human lives.
\end{abstract}

\section{INTRODUCTION}

$\mathrm{T}$ HE work presented in this paper is a year's long efforts which has been started because of an accident, that happened in Pirin Mountain near by the city of Razlok. In the year 2003 a helicopter with water tank flew very low trying to depress the rapidly burning wildland fire in the mountain. Unfortunately the engine oxygen has been vacuumed because of the flames, which caused helicopter's crash with four people crew dead [1]. This accident was very problematic for the Bulgarian society. That is why in the Bulgarian scientific community has been launched in the beginning of 2007 a pilot $\mathrm{PhD}$ program dedicated to the wildland propagation and its modeling opportunities as first attempts for computer based simulations on wildland propagations in Bulgaria.

In 2007 small team from Bulgarian Academy of Sciences (BAS) started adaptation of a US model, which was running in parallel mode. The model was called WRFFire (in 2010 renamed SFIRE). The input data for the model was needed to be first collected for specific test area and second preprocessed for model calibration.

The area of interest for the BAS team was first nearby Sofia, where idealized case has been run and second for real case calibration - test area near by the village of Leshnikovo, region of Harmanli has been chosen.

In this paper we will show the basis of the mathematical calculations and optimizations outlined from the research efforts and the achieved results.

- This work has been supported by the Bulgarian Academy of Sciences Program for support of young researchers No: ДФНП-95-A1 and by the National Science Fund of the Bulgarian Ministry of Education, Youth and Science under Grant FNI I02/20.

\section{WRF-FIRE (SFIRE) MATHEMATICAL BASIS}

The mathematical background of the WRF-Fire model (SFIRE) is as position in the ( $\mathrm{x}, \mathrm{y})$ plane. The model is semiempirical and it represents the spread of the fire in direction of the fire line. This is the so called Rothermel modified formula. The burning region is represented as $\Omega$ for time t, which is represented with the point coordinates $(x, y)$. The formula itself is:

$$
\widetilde{S}=\min \left\{\mathrm{B}_{0}, \mathrm{R}_{0}+\phi_{\mathrm{w}}+\phi_{\mathrm{s}}\right\},
$$

where $\mathrm{B}_{0}$ is the fire spread against the wind direction, $\mathrm{R}_{0}$ is the fire spread in absence of wind, $\phi_{w}=a(\vec{v} \cdot \vec{n})^{b}$ is the wind correction and $\phi_{s}=d \nabla_{z} \cdot \vec{n}$ is the terrain correction,

$\vec{v}$ is wind, $\nabla z$ is terrain variable along the normal $\vec{n}$ of the fire line, $a, b$ и $d$ are constants. In this case WRF-Fire use:

$$
S=\left\{\begin{array}{c}
0, \text { ако } \tilde{S}<0 \\
S_{\max }, \text { ако } \tilde{S}>S_{\max } \\
\tilde{S}, \text { ако } 0 \leq \tilde{S} \leq S_{\max }
\end{array},\right.
$$

where $\mathrm{S}_{\max }$ is max fire spread. After the burning materials are burnt the model decrease them in the points $(\mathrm{x}, \mathrm{y})$ exponentially and that is represented with the formula:

$$
\mathrm{F}(\mathrm{x}, \mathrm{y}, \mathrm{t})=\mathrm{F}_{0}(\mathrm{x}, \mathrm{y}) \mathrm{e}^{-(\mathrm{t}-\mathrm{i} \mathrm{i}(\mathrm{x}, \mathrm{y}) / \mathrm{W}(\mathrm{x}, \mathrm{y})},
$$

where $t$ is the time, $t_{\mathrm{i}}$ is the time for the burning, $F_{0}$ is the initial quantity of the burning materials (before they started to burn) and $W(x, y)$ does not depend on the time, but from the burning materials. The heat transfer released by the fire, is represented in the atmosphere model as layer above the surface, which is situated in height [3]. The burning material quantity is represented by:

$$
\Phi=-A(x, y) \frac{\partial}{\partial t} F(x, y, t) .
$$


This representation is needed because the atmosphere model WRF, does not support border values for heat transfer. The coefficients $B_{0}, R_{0}, S_{\max }, a, b, d, W$ and $A$, which describe the burning materials are measured in laboratory with experiments. For every surface point in the plane the coefficients of the burning materials are represented using the 13 Anderson categories [4]. These categories are developed for US originally and they have been defined by usage of the different sea levels on the surface. WRF-Fire has internally representation of every category and all additional characteristics, which gives opportunity for modifications when the fire is outside US.

WRF-Fire use also level-set functions for the spread of the fire [5]. This approach set as function $\psi=\psi(x, y, t)$, which define for $\Omega$ subregions using the rule:

$$
\Omega(t)=\{(x, y) \in \Omega: \psi(x, y, t)<0\} .
$$

These subregions are burned and the fire line is defined as curve:

$$
\Gamma(t)=\{(x, y) \in \Omega: \psi(x, y, t)=0\} .
$$

The function $\psi(x, y, t)$ satisfy the equation:

$$
\frac{\partial \psi}{\partial t}+S(x, y)|\nabla \psi|=0
$$

which can be solved numerically.

Formulas (1) - (7) are general description how mathematically the fire spread is represented inside the WRF-Fire (SFIRE) model. In the beginning the atmosphere model is interpolating the wind in order to get into the bigger domain of the atmosphere the fire changes. Afterwards is applied numerical method for the level-set function. The next step is to apply quadratic formulas for evaluation of the burnt material. In parallel it is evaluated also the released heat transfer into the atmosphere layers. The last step gives atmospheric change and that trigger the repetition of the model starts again.

\section{EXPERIMENTAL RESULTS WITH WRF-FIRE (SFIRE)}

The experimental results which were obtained after evaluation of the WRF-Fire (SFIRE) model will be presented in this section as a brief summary where we will try to make as much as possible the use of the achieved results.

The first runs with the model were on ideal cases in order to see how the model correspond with the meteorological data and terrain data for the selected zone in south Bulgaria. The run used as inputs coordinates and information for village Leshnikovo, were the domain was set of size 4 by $4 \mathrm{~km}$, with horizontal resolution of $50 \mathrm{~m}$, for the atmosphere mesh, we used 80 by 80 grid cells and with 41 vertical levels from ground surface up to $100 \mathrm{hPa}$. We didn't use nesting to keep the ideal case as basic as possible in order to evaluate the model capacity.

The domain, which we set was located $4 \mathrm{~km}$ west from village Zheleznitsa in the south-east part of Sofia district. The domain was covering the lower part of the forest part of Vitosha mountain.

The ignition line which we used was set in the center of the domain and to ignite it we set $345 \mathrm{~m}$ long line. The model does not consider ignition from point, because the atmospheric model does not cover such measurements. The ignition in parallel has been set to start 2 seconds after the simulation has begun. The results from this first simulation gave us idea how the model can be initialized and what the input data will be if we start simulation with real case forest fire for calibration of the model.

That is why we selected from the national data base in the ministry of forests, food and agriculture fire which has been burning in the period 14-17 August 2009.

For the initialization of the model with real case we had to use algorithm for implementation of the real data in a way WRF-Fire (SFIRE) to recognize it. We set two domains the first was covering area of $48 \mathrm{~km}^{2}$ with resolution $300 \mathrm{~m}$ (160x160). This domain was producing boundary and initial meteorological conditions for the inner domain and in this domain there were no fire simulations.

The inner domain was located in the middle of the coarse domain. The resolution in Domain 2 we set as $60 \mathrm{~m}$ and the area covered is $9.6 \mathrm{~km}^{2}(161 \mathrm{x} 161)$. Domain 2 was centred on the fire ignition line and it was covering the areas of villages Ivanovo, Leshnikovo and Cherna Mogila. This area was located in South-East Bulgaria close to the Bulgarian-Greece border.

Following the description in [6] we get the intermediate fails for topography and fuel. The only difference is in the geogrid program, where the output fail has 2 extra varaibles - NFUEL_CAT and ZSF. NFUEL_CAT is the variable containing the data for the 13th categories of fuel available to bur and ZSF is the variable containing data for the detailed topography. The result as burnt simulated area compared to the real burnt area can be seen on the figures 1 and 2.

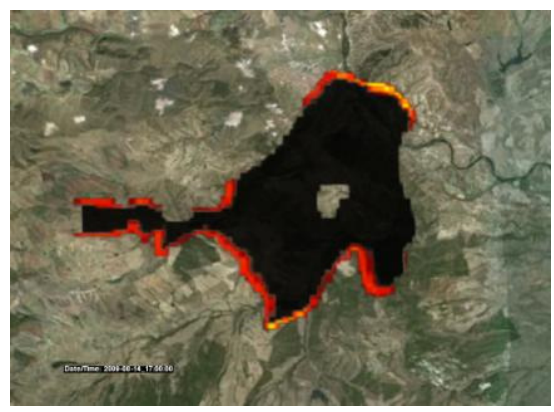

Fig. 1 The simulation fire burnt area 


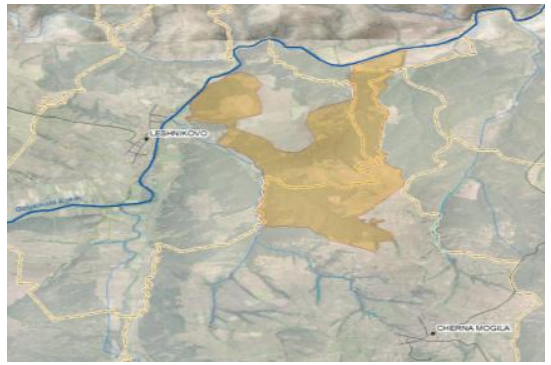

Fig. 2 The real fire burnt area

The simulation showed on figures 1 and 2 was done on the supercomputer at the University of Denver by distant connection. In Table 1 the simulation results are presented according to the number of the cores used.

TABLE 1: THE TIME REQUIRED FOR THE SIMULATION PRESENTED IN SECONDS DEPENDING ON THE NUMBER OF PROCESSORS RUNNING THE PARALLEL EXECUTION OF PROCESSES SHOWING THAT IN 120 CORES THE SIMULATIONS RUN AS REAL TIME. EVERYTHING ABOVE IS FASTER THAN REAL FIRE PROPAGATION.

\begin{tabular}{|l|l|l|l|l|l|l|l|l|l|l|l|l|}
\hline Cores & 6 & 12 & 24 & 36 & 60 & 120 & 240 & 360 & 480 & 720 & 960 & 1200 \\
\hline Fire line propagation in $\mathrm{km}$. & 1.91 & 1.08 & 0.50 & 0.34 & 0.22 & 0.13 & 0.08 & 0.06 & 0.06 & 0.04 & 0.10 & 0.04 \\
\hline Region 1 & 6.76 & 7.05 & 2.90 & 2.06 & 1.20 & 0.73 & 0.45 & 0.32 & 0.26 & 0.23 & 0.24 & 0.17 \\
\hline Region 2 & 0.00 & 0.00 & 0.00 & 0.02 & 0.02 & 0.04 & 0.04 & 0.06 & 0.06 & 0.08 & 0.07 & 0.15 \\
\hline $\begin{array}{l}\text { Total sec. which is the coeff. } \\
\text { for real time }\end{array}$ & 10.59 & 9.21 & 3.91 & 2.75 & 1.64 & 0.99 & 0.61 & 0.44 & 0.37 & 0.31 & 0.44 & 0.26 \\
\hline
\end{tabular}

With this simulations for the test site nearby Harmanli town has been elaborated a methodology for collection, procession and implementation of real data for test sites on Bulgarian territory. The selected model was having as input meteorological data, DEM and only 13 burning classes which led to the idea that we can experiment also with different models like BEHAVE Plus and FARSITE for our next tests.

\section{EXPERIMENTAL IMPLEMENTATION OF BEHAVE PLUS AND FARSITE SIMULATIONS IN THE TEST CASES OF ZLATOGRAD, MADAN AND NEDELINO MUNICIPAL AREAS IN BULGARIA}

In the framework of bilateral cooperation program between Greece and Bulgaria 2007-2013 our team was having the opportunity to work in the Zlatograd forestry department located on the territories of Zlatograd, Madan and Nedelino municipal areas in Bulgaria.

The data we were working on was about fifteen wildfires that occurred in 2011 to 2012 within the Zlatograd municipal territory were provided by the Zlatograd forestry department. Based on initial BehavePlus results using standard fuel models, custom fuel models were developed for some vegetation types not well represented by the US fuel models.

Following evaluation of fuel models with BehavePlus, we performed analyses in FARSITE, a spatial fire growth system that integrates fire spread models with a suite of spatial data and tabular weather, wind and fuel moisture data to project fire growth and behavior across a landscape. We defined our test landscapes using a $500 \mathrm{~m}$ buffer zone around each of the fifteen Zlatograd fires.

Input for FARSITE consists of spatial topographic, vegetation, and fuels parameters compiled into a multilayered "landscape file" format. Topographic data required to run FARSITE include elevation, slope, and aspect. Using the aforementioned $30 \mathrm{~m} \mathrm{DEM}$, we calculated an aspect layer, and then clipped elevation, aspect, and slope rasters to the extent of our fifteen test landscapes. Required vegetation data include fuel model and canopy cover. Fuel models within the 500 $\mathrm{m}$ buffered analysis area for each individual fire were assigned based on our BehavePlus analyses; fuel model assignments were tied to the dominant vegetation for each polygon based on the Zlatograd forestry department's vegetation data. Canopy cover values were visually estimated from orthophoto images and verified with stand data from the Zlatograd forestry department. Additional canopy variables (canopy base height, canopy bulk density, and canopy height) that may be included in the landscape file were omitted, as these variables are most important for calculating crown fire spread or the potential for a surface fire to transition to a crown fire. None of the fifteen fires analyzed experienced crown fire.

Tabular weather and wind files for FARSITE were compiled using the weather and wind data from TV Met, Bulgarian meteorological company that included hourly records. Tabular fuel moisture files were created using the fine dead fuel moisture values calculated for the BehavePlus analyses for 1-hr timelag fuels. The 10-hr fuel moisture value was estimated by adding $1 \%$ to the 1 -hr fuel moisture and the $100-\mathrm{hr}$ fuel moisture was generally calculated by adding $3 \%$ to the 1-hr fuel moisture. The live fuel moisture values previously estimated for BehavePlus analyses were used to populate live herbaceous and live woody moisture values.

All simulations performed in FARSITE used metric data for inputs and outputs. An adjustment value was not used to alter rate of spread for standard fuel models, rather custom fuel models were created. Crown fire, embers from torching trees, and growth from spot fires were not enabled.

As an example of one of our successful FARSITE runs, we present the results from a single wildfire that burned in grassland vegetation, for which we developed custom fuel models. This fire occurred on 
August 30, 2011, starting at 1400 and ending around 1800 , and burned a total area of 0.3 ha. We used the following input parameters to model this small grassland fire in FARSITE:

Fuel moisture values: 6\% (1-hr), 7\% (10-hr), 9\% (100-hr), $45 \%$ (live herbaceous), and $75 \%$ (live woody);

Daily maximum temperatures: $17-21^{\circ} \mathrm{C}$;

Daily minimum relative humidity: $24-50 \%$;

Winds: generally from the west-southwest at $1-2 \mathrm{k}$ h-1

The fire size as calculated using FARSITE was 0.5 ha, which seems reasonable considering the modeled size would not have included the suppression actions that most likely occurred given the close proximity of a village to this fire figure 3 .
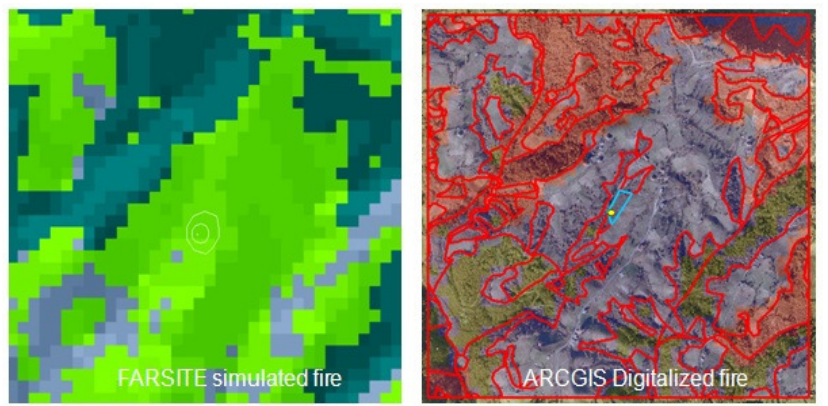

Figure 3: FARSITE run for a grassland fire, where size of the fire is very close to the real one, but the shape is different, because of wind information discrepancies

From this modeled fire we were able to estimate that grasslands and any grass and shrub covered areas will probably have the need to be further modeled before using as inputs for standard simulations with FARSITE or any similar tool in future. However FARSITE and BehavePlus provided reasonable outputs for future work in the field of fire behavior fuel modeling on the Bulgarian territory. The work done in more details is described in [7],[8],[9],[10].

\section{CONCLUSION}

The presented paper was having as main aim to provide a broader view on the tested modeling options for the Bulgarian wild land fires and the achieved results. There are still a lot of issues to be solved in the data preparation phase and the accuracy of the meteorological inputs. However the achieved results after all computations give promising options for future implementation of this modeling tools for more operational use in the responsible authorities first response facilities. With the presented test is given an idea what kind of simulations are more accurate when past wildland fires are modeled. Also the burning materials representations is very crucial which can be seen through the presented examples. This field still need to be more elaborated, but the first results gave good basis on how we can continue our future work.

\section{ACKNOWLEDGMENT}

N. D. thanks to the program for career development of young scientists, BAS with contract No: ДФНП-95-A1 and to the National Science Fund of the Bulgarian Ministry of Education, Youth and Science under Grant FNI I02/20.

\section{REFERENCES}

[1] http://news.ibox.bg/news/id 1888536796 (In Bulgarian)

[2] Rothermel, R. C. (1972) A mathematical model for predicting fire spread in wildland fuels. Research Paper INT-115. Ogden, UT: US Department of Agriculture, Forest Service, Intermountain Forest and Range Experiment Station, pp. 1-40.

[3] Patton, E.G., Coen, J.L.: WRF-Fire: A coupled atmosphere-fire module for WRF. In: Preprints of Joint MM5/Weather Research and Forecasting Model UsersWorkshop, Boulder, CO, June 2225. NCAR (2004) $221223 \mathrm{http} / / /$ www.mmm.ucar.edu/mm5/workshop/ws04/ Session9/PattonEdward.pdf

[4] Anderson, H.E.: Aids to determining fuel models for estimating fire behavior.USDA Forest Service, Intermountain Forest and Range Experiment Station, Research Report INT-122 (1982)http : //www.fs.fed.us/rm/pubsint/intgtr122.html.

[5] http://ccm.ucdenver.edu/wiki/Jan Mandel/Blog/2010_Dec 2011 Jan

[6] http://www.openwfm.org/wiki/How to run WRFFire_with_real_data\#Downloading_high_resolution_elevation_data

[7] Dobrinkov G., Dobrinkova N." "Input Data Preparation for Fire Behavior Fuel Modeling of Bulgarian Test Cases (Main Focus on Zlatograd Test Case).", $10^{\text {th }}$ International Conference on "Large-Scale Scientific Computations" LSSC'15, Sozopol 8-12 June 2015, Lecture Notes in Computer Science 9374, ISSN 0302-9743, ISSN 1611-3349 (electronic), ISBN: 978-3-319-26519-3, DOI 10.1007/978-3-31926520-9, Springer Germany, pp. 335-342, 2015.

[8] Dobrinkova N., Hollingsworth L., Heinsch F.A., Dillon G., Dobrinkov G., "Bulgarian fuel models developed for implementation in FARSITE simulations for test cases in Zlatograd area". (E-proceeding: http://www.treesearch.fs.fed.us/pubs/46778) Wade DD \& Fox RL (Eds), Robinson ML (Comp) (2014) 'Proceedings of $4^{\text {th }}$ Fire Behavior and Fuels Conference', 18-22 February 2013, Raleigh, NC and 1-4 July 2013, St. Petersburg, Russia. (International Association of Wildland Fire: Missoula, MT), p.513 - p.521.

[9] Dobrinkov G., Dobrinkova N., "Wildfire behavior modeling data preparation for FARSITE simulations in Bulgarian test cases", $5^{\text {th }}$ International Conference on Cartography \& GIS \& Seminar with EU cooperation on Early Warning and Dissaster/Crisis Management 15-21 June 2014, Proceedings Vol.2, ISSN:1314-0604, 2014, Riviera, Bulgaria, p.763- p. 770 .

[10] N.Dobrinkova, G. Dobrinkov, "Farsite and WRF-Fire models, Pros and Cons For Bulgarian Cases", $9^{\text {th }}$ International Conference on "Large-Scale Scientific Computations" LSSC'13, Sozopol 3-7 June 2013, Lecture Notes in Computer Science 8353, ISBN: 978-3-66243879-4, Springer Germany, pp. 382-389, 2014. 